\title{
Derecho de acceso a la información pública: comentarios a un fallo clave de la Corte Europea de Derechos Humanos
}

Este comentario, junto a los documentos que analiza, está disponible en www.anuariocdh.uchile.cl

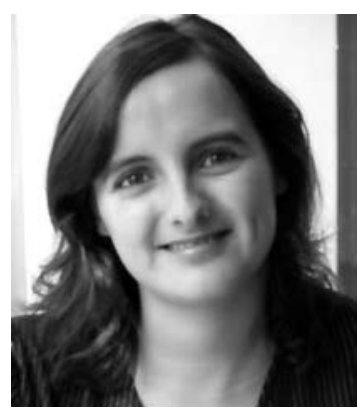

\section{Constanza Toro Justiniano}

Abogada, Licenciada en Ciencias Jurídicas y Sociales por la Universidad de Chile (distinción máxima). Actualmente se desempeña como investigadora del Programa Derechos Humanos y Democracia, del Centro de Derechos Humanos de la Facultad de Derecho de la misma Casa de Estudios.

ctoro@derecho.uchile.cl

\section{RESUMEN}

Este artículo examina el fallo de la Corte Europea de Derechos Humanos en el caso "Társaság a Szabadságjogokért Vs. Hungría", con el objeto de evaluar los avances y/o desafíos que esta sentencia implica para el reconocimiento y plena vigencia del derecho de acceso a información pública.

\section{Introducción}

El 14 de abril del año 2009 la Corte Europea de Derechos Humanos dictó sentencia en el caso de "Társaság a Szabadságjogokért Vs. Hungría". Para quienes trabajan en el campo del derecho de acceso a la información pública, esta sentencia constituye un hito en el reconocimiento de este derecho a nivel europeo ${ }^{1}$. En este artículo me propongo examinar los avances e implicancias que puede acarrear un fallo como éste, pero también los puntos que aún restan por desarrollar y profundizar en la jurisprudencia venidera.

\section{a. El caso sometido ante la Corte Europea de Derechos Humanos}

El fallo objeto de este comentario recayó sobre el siguiente caso: el año 2004 un miembro del Parlamento húngaro, en conjunto con otros individuos, interpuso un reclamo judicial ante el Tribunal Constitucional con el objeto de que se revisaran unas modificaciones del Código Penal relativas a delitos de estupefacientes. Meses después, una organización no gubernamental-dedicada

\footnotetext{
Así lo han declarado organizaciones como "Access Info Europe" y "Periodismo por el Acceso a la Información Pública". Notas de prensas disponibles en http://www.access-info.org/documents/documents/09_04_14_European_Court_Access_ to_Info_PR_en.pdf; http://www.periodismo-aip.org/noticia-detalle.php?id=48; http://tasz.hu/en/news/echr; http://merlin. obs.coe.int/iris/2009/7/article1.
} 
a la promoción de derechos fundamentales, al fortalecimiento de la sociedad civil y el Estado de Derecho, y entre cuyos ámbitos de acción está el análisis de las políticas públicas relativas a drogas- solicitó al Tribunal Constitucional acceso a dicho reclamo judicial aún pendiente. Para ello se basó en lo dispuesto por la Ley de Protección de Datos Personales y de Publicidad de los Datos de Interés Público², de 1992.

El Tribunal Constitucional denegó dicha petición sin consultar a los requirentes (el miembro del Parlamento), argumentando que no podía dar acceso a un reclamo pendiente sin la aprobación de sus requirentes. La ONG recurrió a los tribunales ordinarios de justicia para insistir en su petición de acceso a información. Entretanto, el Tribunal Constitucional adoptó una decisión acerca del requerimiento del parlamentario, que contenía un resumen del mismo y que fue hecho público.

A pesar de que el procedimiento ante el Tribunal Constitucional ya había finalizado, la Corte Regional de Justicia denegó la petición de la ONG, pues consideró que el reclamo solicitado no podía considerarse como "datos" en el sentido de la legislación húngara ${ }^{3}$.

La ONG apeló esta decisión, y aún más, solicitó acceso al reclamo aunque fuese después de que se eliminara la información personal que pudiera contener. La Corte de Apelaciones confirmó la denegatoria, aunque precisó que el reclamo podía contener "datos", pero estimó que dichos datos debían considerarse personales y por lo tanto no era posible acceder a ellos sin el consentimiento de su autor. No hizo referencia a la posibilidad de entregar dicha información eliminando la referencia a datos personales.

La ONG estimó que la decisión adoptada por las Cortes húngaras denegando el acceso al reclamo judicial interpuesto por un miembro del Parlamento vulneraba el derecho de acceder a información de interés público. Es por ello que acudió ante la Corte Europea de Derechos Humanos alegando una violación al artículo $10^{\circ}$ de la Convención Europea de Derechos Humanos, disposición que recoge el derecho de libertad de expresión ${ }^{4}$.

\section{b. Posición de las partes ante la Corte Europea de Derechos Humanos}

Ante la Corte Europea de Derechos Humanos, el Estado no controvirtió la pertinencia de alegar la infracción del artículo $10^{\circ}$ de la Convención Europea de Derechos Humanos. Por el contrario, su defensa se basó en la posibilidad de establecer ciertas restricciones legítimas de este derecho ${ }^{5}$.

2 Ley № 63 de 1992 sobre Protección de Datos Personales y de Publicidad de los Datos de Interés Público. La sección 19 de esta normativa regula el acceso a la información.

3 La segunda y tercera secciones de la normativa húngara definen lo que debe entenderse por información pública y datos personales. De acuerdo a esta legislación, información pública es "todo dato, fuera de los datos personales, relacionado con las actividades o procesado por un órgano o persona que lleva a cabo tareas estatales o municipales u otras funciones públicas de acuerdo a lo que establezca la ley".

4 Convención Europea de Derechos Humanos, artículo 10. Libertad de expresión. 1) Toda persona tiene derecho a la libertad de expresión. Este derecho comprende la libertad de opinión y la libertad de recibir o de comunicar informaciones o ideas sin que pueda haber injerencia de autoridades públicas y sin consideración de fronteras. El presente artículo no impide que los Estados sometan las empresas de radiodifusión, de cinematografía o de televisión a un régimen de autorización previa. 2) El ejercicio de estas libertades, que entrañan deberes y responsabilidades, podrá ser sometido a ciertas formalidades, condiciones, restricciones o sanciones, previstas por la ley, que constituyan medidas necesarias, en una sociedad democrática, para la seguridad nacional, la integridad territorial o la seguridad pública, la defensa del orden y la prevención del delito, la protección de la salud o de la moral, la protección de la reputación o de los derechos ajenos, para impedir la divulgación de informaciones confidenciales o para garantizar la autoridad y la imparcialidad del Poder Judicial".

5 El párrafo 2 del artículo $10^{\circ}$ del Convenio establece que "El ejercicio de estas libertades, que entrañan deberes y responsabilidades, podrá ser sometido a ciertas formalidades, condiciones, restricciones o sanciones, previstas por la ley, que constituyan medidas necesarias, en una sociedad democrática, para la seguridad nacional, la integridad territorial o la seguridad pública, la defensa del orden y la prevención del delito, la protección de la salud o de la moral, 
El Estado se basó en los argumentos dados por la Corte de Apelaciones húngara, esto es, estimó que en el reclamo existía información que podía considerarse como "datos", pero que éstos eran de carácter "personal" en tanto el reclamo judicial contenía información personal y opiniones del peticionario. Es decir, la negativa se fundaría en el legítimo objetivo de proteger los derechos ajenos.

La ONG, en tanto, basó su petición ante la Corte Europea demostrando el interés público envuelto en la petición de información. Para ello, comenzó por aclarar que la organización estaba interesada en la política estatal sobre drogas, y que fue en base a ese interés que solicitó acceder al reclamo que se realizó ante el Tribunal Constitucional. La negativa frente a esta petición entorpeció la posibilidad de la organización de cumplir con su rol público y de contribuir al debate público sobre estas materias. La ONG insistió en su rol público, similar al que cumple la prensa, pues permite a los ciudadano/as informarse y formarse una opinión relativa a las políticas públicas sobre drogas y respecto de lo que opinan y defienden personajes públicos ${ }^{6}$.

\section{c. Decisión de la Corte Europea de Derechos Humanos}

Frente a este dilema, la Corte Europea de Derechos Humanos examinó en primer lugar si había existido una afectación del derecho contenido en el artículo $10^{\circ}$ de la Convención. A lo largo de este análisis, la Corte reconoció la vinculación entre la libertad de expresión y el derecho a acceder a información de carácter público, y examinó las exigencias que impone al Estado dicho artículo.

A este respecto, la Corte estableció que en virtud del artículo $10^{\circ}$ no le está permitido al Estado establecer restricciones arbitrarias, en tanto éstas podrían transformarse en una forma de censura indirecta. Asimismo, tampoco está permitido que la autoridad estatal cree obstáculos para recibir información. En este caso, la Corte estimó que la información que se requería era de carácter público y que las autoridades crearon un obstáculo administrativo para acceder a la misma. Por lo tanto, la primera conclusión de la Corte es que hubo una afectación en los derechos garantizados en el artículo $10^{\circ}$ de la Convención.

Como segundo paso en su razonamiento, la Corte se abocó a examinar si dicha afectación fue justificada. Para examinar la legitimidad de la restricción a la libertad de expresión -de acceso a información pública en este caso- evaluó si ésta estaba establecida en la ley, si perseguía un objetivo legítimo y si resultaba necesaria en una sociedad democrática.

Para la Corte, el primer requisito - establecimiento de la restricción por ley-fue satisfecho, pues el Estado se basó en la ley de datos húngara ${ }^{7}$. En cuanto al segundo requisito-objetivo legítimo-en tanto el Estado alegó que la negativa se justificaba en la protección de los derechos de terceros, estimó que este requisito también estaba satisfecho. Sin embargo, es en el tercer requisito -restricción necesaria en una sociedad democrática- donde la Corte estimó que el Estado infringió el artículo $10^{\circ}$, pues a su juicio la negativa de acceso a la información solicitada habría obstaculizado la libre circulación de información y el debate público. Es en estas reflexiones en las que la Corte desarrolló el alcance y la importancia del derecho de acceso a información pública.

la protección de la reputación o de los derechos ajenos, para impedir la divulgación de informaciones confidenciales o para garantizar la autoridad y la imparcialidad del Poder Judicial".

6 Para mayor información sobre la postura a favor del acceso a la información, es posible revisar la intervención de las organizaciones Open Society Justice Initiative, the Financial Times Ltd y Access Info Europe, disponible en: http://www. soros.org/initiatives/justice/litigation/hungary/hungary_20080901.pdf

7 Ob. cit., nota 2. 
Antes de examinar los aportes y temas pendientes que planteó esta sentencia, conviene revisar brevemente cuál es el avance que ha experimentado el derecho de acceso a información.

\section{El derecho de acceso a información pública}

Realizar un repaso completo de los orígenes y posteriores desarrollos del derecho de acceso a información pública excede el ámbito de este comentario ${ }^{8}$. Basta aquí con decir que el derecho de acceso a información pública no es una prerrogativa reciente. La primera ley formal de acceso a la información fue aprobada en Suecia ya en el año 1766. No obstante, pasaría tiempo para que se fueran consolidando en la cultura jurídica las nociones de libertad de prensa, libertad de información ${ }^{9}$, libertad de expresión ${ }^{10}$, etc. De estos conceptos surge la idea del derecho de acceso a la información pública.

Diversos instrumentos jurídicos internacionales consagraron la libertad de expresión en sus articulados, con expresiones que incluyen el derecho a "investigar y recibir informaciones"; "la libertad de investigación"; "libertad de buscar, recibir y difundir informaciones", etc. A partir de estas expresiones fue reconociéndose un derecho a exigir información cuando ésta recae sobre temas de interés público.

Con el paso del tiempo, fue necesario regular con mayor detalle esta prerrogativa: establecer qué información era de carácter público, quién debía otorgarla, bajo qué procedimiento, en qué ocasiones podía restringirse este derecho, etc. Principios internacionales elaborados a partir del activismo de la sociedad civil ${ }^{11}$, así como las diversas leyes nacionales que progresivamente se dictaron ${ }^{12}$, han abordado estas materias. En último término, también en el plano internacional se han logrado avances que plasman el desarrollo de este derecho ${ }^{13}$.

Ni Europa ni Latinoamérica escapan de esta corriente normativa por lo que era plausible que los tribunales, tanto nacionales como internacionales, recibieran casos en los que tendrían que pronunciarse sobre el derecho de acceso a información pública. En América Latina el pronunciamiento clave en esta materia se dio por la Corte Interamericana de Derechos Humanos el 19 de septiembre de 2006, en el caso Claude Reyes y otros vs. Chile ${ }^{14}$. Casi tres años más tarde, la Corte Europea de Derechos Humanos tuvo la ocasión -en este caso- de pronunciarse sobre esta

8 Para un estudio completo de las leyes de acceso a información, ver ACKERMAN, John y SANDOVAL, Irma. Leyes de Acceso a la Información en el Mundo. Cuadernos de Transparencia (7) del Instituto Federal de Acceso a la Información Pública, México, 2005.

9 Ya en 1946 la Asamblea General de Naciones Unidas consagraba la libertad de información. En su Resolución 59(I) del 14 de diciembre de dicho año declaraba que "La libertad de información es un derecho humano fundamental y piedra de toque de todas las libertades a las cuales están consagradas las Naciones Unidas".

10 Es un derecho reconocido en la Declaración Universal de Derechos Humanos (artículo 19), y a partir de ahí, en el resto de las Convenciones sobre Derechos Humanos (artículo $10^{\circ}$ de la Convención Europea de Derechos Humanos; artículo IV de la Declaración Americana de los Derechos y Deberes del Hombre; artículo $19^{\circ}$ del Pacto Internacional de Derechos Civiles y Políticos; artículo $13^{\circ}$ de la Convención Americana sobre Derechos Humanos).

11 Entre los más destacados cabe mencionar la Declaración de Chapultepec de 1994; los Principios de Johannesburgo sobre la Seguridad Nacional, la Libertad de Expresión y el Acceso a la Información de 1996; y los Principios de Lima del 2000.

12 Actualmente existen más de 70 países que cuentan con legislación relativa al acceso a la información. Un estudio exhaustivo de las leyes alrededor del mundo realizado por la organización Privacy International puede ser encontrado en http://www.privacyinternational.org/foi/foisurvey2006.pdf

13 A nivel Interamericano, se espera para el segundo semestre el lanzamiento de la Ley Modelo sobre Acceso a la Información Pública. El Consejo de Europa, en tanto, adoptó el primer tratado sobre derecho a la información (Convención para el Acceso a Documentos Oficiales) el 27 de noviembre del 2008.

14 Para un examen del caso Claude Reyes Vs. Chile ver MUÑOZ, Alex. Chile y el Acceso a la Información Pública. Comentarios sobre un nuevo fallo adverso de la Corte Interamericana. Anuario de Derechos Humanos 2007, (3). Centro 
materia. Corresponde ahora determinar si la Corte Europea ha aportado nuevos elementos en este desarrollo normativo, si ha recogido los últimos avances y qué aspectos aún quedan por pulir.

En definitiva, el derecho de acceso a la información pública es un derecho cuyos orígenes son relativamente remotos. Sin embargo, se trata de un derecho que lleva varios años de desarrollo progresivo y en ese contexto, lo que tenga que aportar la jurisprudencia puede ser de vital importancia para el fortalecimiento de una cultura jurídica y política respetuosa de este derecho.

\section{Análisis del fallo: aportes y temas pendientes}

Como dijimos anteriormente, este caso constituyó una gran oportunidad para la Corte Europea de Derechos Humanos de pronunciarse claramente y con fuerza sobre el derecho de acceder a información pública. En este sentido, existen varios puntos de este fallo que merecen ser destacados por constituir un aporte al fortalecimiento de este derecho. Pero, junto con destacar los aportes que significó este pronunciamiento es necesario señalar también aquellos aspectos en que la Corte se limitó a recoger, tímidamente a veces, los avances ya consolidados en la doctrina, desaprovechando así la oportunidad para esclarecer algunos aspectos de este derecho.

\section{a. Reconocimiento del derecho de acceso a información pública}

Un primer aspecto fundamental que puede extraerse de este fallo es el reconocimiento del derecho de acceso a la información pública como derecho humano. Tanto la Corte Europea como las partes, en este caso, asumen la vinculación entre el derecho humano de libertad de expresión y el derecho de acceder a información de carácter público. Es específicamente a partir de la interpretación de la noción de "libertad de recibir información", que la Corte reconoce la existencia de un derecho de acceso a información ${ }^{15}$. Por lo tanto, ya no es materia de controversia que el derecho de libertad de expresión incluye un derecho de acceder a información pública.

Por la misma vía de reconocer que el derecho de acceder a información pública forma parte del derecho de libertad de expresión, la Corte Interamericana de Derechos Humanos reafirmó el rango de derecho humano de esta prerrogativa. Sin embargo, la Corte Interamericana puso mayor énfasis en la vinculación que existe entre ambas nociones, aclarando que "los derechos a 'buscar' y a 'recibir' 'informaciones', protege[n] el derecho que tiene toda persona a solicitar el acceso a la información bajo el control del Estado [...]. De esta forma, el derecho a la libertad de pensamiento y de expresión contempla la protección del derecho de acceso a la información bajo el control del Estado, el cual también contiene de manera clara las dos dimensiones, individual y social, del derecho a la libertad de pensamiento y de expresión, las cuales deben ser garantizadas por el Estado de forma simultánea libertad de expresión y acceso a información"16.

En otras instancias regionales el reconocimiento del carácter de derecho humano del acceso a la información ha sido aún más explícito. Así, por ejemplo, en octubre del año 2000, la Comisión Interamericana de Derechos Humanos aprobó la Declaración de Principios sobre la Libertad de Expresión elaborada por la Relatoría Especial, que en su cuarto principio reconoce que "[e]l acceso a la información en poder del Estado es un derecho fundamental de los individuos. Los Estados

de Derechos Humanos, Facultad de Derecho de la Universidad de Chile, Santiago, Chile, 2007. Versión electrónica disponible en http://www.cdh.uchile.cl/anuario03/7-SeccionNacional/anuario03_sec_nacionallI_MunozWilson.pdf.

15 Párrafo 35 de la sentencia.

16 Párrafo 77 de la sentencia en el caso Claude Reyes Vs. Chile. 
están obligados a garantizar el ejercicio de este derecho". Asimismo, los Principios de Lima ${ }^{17}$, comienzan por establecer "[e]l acceso a la información como derecho humano"18.

De todas formas -aunque a nivel doctrinario la vinculación entre el derecho de acceso a la información pública y el derecho de libertad de expresión ya tiene amplia aceptación- este reconocimiento reviste gran importancia, ya que el hecho de que sean los Estados y los órganos jurisdiccionales quienes reconozcan esta vinculación, permite hacer exigible el derecho de acceso a la información en sede judicial, a la vez que se delimitan las excepciones posibles al derecho.

\section{b. Derecho de acceso a información pública y debate público}

Un segundo aspecto que merece ser destacado en el fallo es la reflexión de la Corte en torno a la importancia de este derecho. La Corte reconoció la importancia de proteger este derecho para efectos de permitir la libertad de prensa, para permitir la libre circulación de información y de ideas, y lo más importante, para promover el debate público en materias de legítimo interés público. De esta manera, la Corte recogió una de las principales funciones que se le adscriben al derecho de acceso a la información pública.

La Comisión Interamericana de Derechos Humanos ha sabido resumir en forma acertada las principales funciones del derecho de acceso a la información pública y la consiguiente importancia del mismo. En palabras de la Comisión, "[l]a trascendencia del derecho de acceso a la información se pone de manifiesto en tres ámbitos específicos. El derecho de acceso a la información es una herramienta crítica para la participación democrática, el control del funcionamiento del Estado y la gestión pública, y el control de la corrupción"119. Son los dos primeros ámbitos los que destaca la Corte Europea en este fallo, introduciendo algunos elementos que vale la pena destacar.

La Corte Europea destacó la función de fiscalización social aparejada al derecho de acceso a información, pues reconoció que afectar el derecho de recibir información interfiere con el ejercicio de las funciones de "vigilancia social"20. La Corte Interamericana también fue explícita en este punto y dedicó varios párrafos de la sentencia en el Caso Claude Reyes a desarrollar la vinculación entre acceso a información, democracia y control democrático ${ }^{21}$.

17 Para ver el texto completo de los denominados Principios de Lima de noviembre de 2000, ver http://www.cidh.oas.org/ relatoria/showarticle.asp?artID $=158 \& \mid \mathrm{ID}=2$

18 Resulta interesante plantear si el reconocimiento del derecho de acceso a información como derecho humano debería ser adscrito a la libertad de expresión o como un derecho humano autónomo. Analizar en profundidad esta cuestión excede al análisis de este fallo, sin embargo, cabe señalar que la configuración autónoma del derecho de acceso a información como derecho humano, permitiría reconocer algunas de sus particularidades que lo distinguen de la libertad de expresión. Por ejemplo, el derecho de libertad de expresión se reconoce en forma independiente a si la información que circula es veraz o no. Tratándose del acceso a la información pública, en cambio, se reconoce un deber de veracidad por parte del Estado que debe brindar la información pública. De todas formas, resulta lógico que órganos de carácter jurisdiccional como las respectivas Cortes de Derechos Humanos vinculen el derecho de acceso a información con el de libertad de expresión, pues es este último el que les permite acudir al texto normativo de las respectivas Convenciones, que son las que otorgan competencia material a las Cortes para conocer de estos casos.

19 Informe Anual de la Relatoría Especial para la Libertad de Expresión, de la Comisión Interamericana de Derechos Humanos, año 2009. Énfasis añadido.

20 La Corte utiliza la expresión "social watchdog", sugiriendo que determinados actores -entre ellos la prensa, pero no únicamente ésta- actúan como "perros guardianes" del gobierno y la gestión pública.

21 El párrafo más claro en este aspecto, es el 87 en el cual declara que "El control democrático, por parte de la sociedad a través de la opinión pública, fomenta la transparencia de las actividades estatales y promueve la responsabilidad de los funcionarios sobre su gestión pública. Por ello, para que las personas puedan ejercer el control democrático es esencial que el Estado garantice el acceso a la información de interés público bajo su control. Al permitir el ejercicio de ese control democrático se fomenta una mayor participación de las personas en los intereses de la sociedad". 
La Corte Europea estableció expresamente, además, que esta función de fiscalización, que previamente le había sido reconocida a la prensa, también puede ser llevada a cabo por otros agentes como organizaciones de la sociedad civil. Respecto a la función de crear foros para el debate público, la Corte consideró que "no está limitada a los medios de comunicación o periodismo profesional. En el presente caso, la preparación del foro de debate público estaba conducido por una organización no gubernamental"22. Se amplió de esa forma la noción de fiscalización -vía debate público- y su necesaria contrapartida, el deber de rendición de cuentas por parte del gobierno ${ }^{23}$.

La Corte Europea examinó cómo se afecta el debate público, y la fiscalización que de ahí surge, si se restringe el derecho de acceder a información pública. En este análisis, es interesante notar que la Corte reconoció una nueva forma de censura en el manejo discrecional de un monopolio de información. En este sentido, la Corte declaró que "el monopolio de la información en manos del Tribunal Constitucional constituyó así una forma de censura" ${ }^{\prime 24}$.

Otro aspecto de gran importancia es el análisis que hace la Corte Europea respecto del ámbito de privacidad de los personajes públicos. A este respecto, la Corte se limita a declarar que "sería fatal para la libertad de expresión en la esfera de la política si las figuras públicas pudieran censurar a la prensa y el debate público en nombre de sus derechos de personalidad, alegando que sus opiniones sobre materias de interés público se relacionan con su persona y por lo tanto constituyen datos privados que no pueden revelarse sin su consentimiento" ${ }^{25}$. Con esta declaración, la Corte reconoce un principio defendido por la doctrina en esta materia, y es que tratándose de personajes públicos su ámbito de privacidad debe ser necesariamente más reducido en tanto el ejercicio de sus funciones debe quedar sujeto a escrutinio social ${ }^{26}$. Esto nos Ileva a la necesidad de determinar en qué circunstancias le sería lícito al Estado negar la información.

\section{c. Límites y excepciones del derecho}

Esta materia es fundamental a la hora de configurar el derecho de acceso a la información pública. En este caso en particular, la cuestión debatida se centraba en determinar en qué consistía un dato privado versus información pública, y cómo manejar el legítimo objetivo de proteger los derechos (de privacidad) de terceros.

A mi juicio, éste es el punto más débil del fallo, pues si bien la Corte reconoce que está en presencia de un tema de interés público, no desarrolla con precisión cuáles serían los contornos de los derechos de privacidad. Desaprovecha así una oportunidad para aclarar qué tratamiento debe darse a los datos personales, hasta qué punto podría ser válido como causal de denegación de la información, etc.

La única declaración en este punto ${ }^{27}$ no aclaró qué constituye efectivamente un dato personal y cómo debe procederse en caso de que concurran a la vez datos de interés público y datos

22 Párrafo 27 de la sentencia.

23 Para mayor información sobre el concepto de rendición de cuentas ver SCHEDLER, Andreas ¿Qué es la rendición de cuentas? Cuadernos de Transparencia, (3), Instituto Federal de Acceso a la Información Pública, México, 2005.

24 Párrafo 28 de la sentencia.

25 Párrafo 37 de la sentencia.

26 Principio N ${ }^{\circ} 11$ de la Declaración de Principios sobre Libertad de Expresión de la Comisión Interamericana de Derechos Humanos lo señala al establecer que "Los funcionarios públicos están sujetos a un mayor escrutinio por parte de la sociedad".

27 Ob. cit. Nota 24. 
privados $^{28}$. Tampoco se hizo cargo de los argumentos de las partes en cuanto a la necesidad de contar con el consentimiento del afectado, ¿en qué casos se requiere el consentimiento del afectado? ¿Cómo debe requerírsele?

La Corte tuvo la oportunidad de enfatizar la necesidad de interpretar las excepciones al acceso a la información -incluida la causal de protección de derechos de tercero o de privacidad- de forma restrictiva. Podría haber desarrollado cómo tratándose de casos en que se pretende proteger la vida privada de terceros, se trata de excepciones que se guían por el criterio de la prueba de interés publico ${ }^{29}$, y que por lo tanto demostrándose el interés público en divulgar dicha información, ésta debe ser dada a conocer.

También hubiera sido interesante que la Corte hubiese destacado cómo el presente caso demostraba que el acceso a información pública no es un derecho que se limite al Poder Ejecutivo del Estado ${ }^{30}$, y que debe alcanzar también a organismos autónomos como los Tribunales Constitucionales, al Poder Legislativo y al Judicial.

\section{Conclusiones}

En suma, se trata de un fallo importante para la consolidación del derecho de acceso a información. Sin duda constituye un avance en el reconocimiento de este derecho y de las funciones que está Ilamado a cumplir en una sociedad democrática. No obstante, la Corte Europea toma este paso adelante con demasiada cautela ${ }^{31}$. A diferencia de la Corte Interamericana, no desarrolla mayormente sus reflexiones y desaprovecha de ese modo la oportunidad para enfatizar algunos aspectos que podrían haber fortalecido la defensa del derecho de acceso a información pública.

Es de esperar que este fallo -tal como sucedió con el caso Claude Reyes en Latinoamérica- ${ }^{32}$ tenga un efecto práctico en la cultura política de los países que aún no asimilan este derecho en sus administraciones públicas. En este sentido, esta sentencia puede transformarse en una herramienta que contribuya, ya no sólo a la consolidación del derecho en el plano jurídico, sino en la mentalidad de la administración pública. Es necesario asumir no solo el deber de transparentar la función pública, sino también el desafío de derrotar las resistencias frente a la rendición de cuentas por parte de la sociedad. Esta fiscalización debe extenderse también a aquellos entes que ejercen funciones de control y en quienes la resistencia a estar sometidos a revisión suele ser mayor.

28 La doctrina desarrolla cómo debe procederse en estos casos. Se reconoce, por ejemplo, el denominado principio de divisibilidad en virtud del cual, si hubiera información que puede ser conocida e información que debe denegarse en virtud de causa legal, se dará acceso a la primera y no a la segunda.

29 Para mayor información sobre esta distinción ver LÓPEZ-AYLLÓN, Sergio y POSADAS, Alejandro. Las pruebas de daño e interés público en materia de acceso a información. Una perspectiva comparada. Derecho Comparado de la Información (9) enero-junio de 2007, pp. 21-65.

30 Varias leyes en materia de acceso a información -entre ellas la chilena- incurren en esta limitación del derecho, en el sentido de circunscribir la posibilidad de solicitar información sólo al Poder Ejecutivo del Estado, excluyendo de ese modo a los poderes Legislativo y Judicial.

31 En el mismo sentido, Helen Darbishire -directora ejecutiva de Access Info Europe- comentó esta sentencia declarando que "este pronunciamiento es una cautelosa confirmación de que el derecho de acceso a información es un derecho humano". Ver notas de prensa señaladas en nota 1.

32 A raíz de este fallo, Chile promulgó la Ley № 20.285 sobre Acceso a Información Pública. Asimismo, este fallo tuvo eco en la Jurisprudencia de la región, la cual se ha basado en este fallo para resolver cuestiones relativas al derecho de acceder a la información pública. Ver en este sentido, Alcance del derecho al acceso a la información pública: Diálogo Lurisprudencial (3) julio-diciembre 2007, en donde se menciona la jurisprudencia paraguaya que se basó en este fallo para determinar al alcance de este derecho. Documento disponible en http://www.juridicas.unam.mx/publica/librev/ rev/dialjur/cont/3/cnt/cnt17.pdf. 
No es de extrañar que este fallo se dé en el contexto de un país del este de Europa -Hungría- en donde si bien existe una legislación sobre datos, aún puede persistir una cultura política opaca. Una situación similar sucede en muchos países de nuestra región, en donde recién se están incorporando normativas sobre estas materias, pero aún resta por superar un pasado autoritario y lograr así una cultura jurídica y política transparente y dispuesta a rendir cuentas de sus actos ${ }^{33}$.

33 Para mayor información sobre la relación entre formas autoritarias de gobierno y su disposición frente a la transparencia, ver: RODRÍGUEZ, Jesús. Estado y Transparencia: Un paseo por la filosofía política. Cuadernos de Transparencia (4) Instituto Federal de Acceso a la Información Pública, México, 2004. 
